\title{
Sex Determination by Applying Discriminant Functional Analysis on Patellar Morphometry
}

\author{
I. Kayalvizhi ${ }^{1}$, S. Arora ${ }^{2}$, B. Dang ${ }^{3}$, Swati Bansal ${ }^{4}$, R. K. Narayan ${ }^{5}$ \\ ${ }^{1,2,3,4,5}$ Pt. B. D. S. PGIMS, Department of Anatomy, Rohtak, Haryana -124001, India
}

\begin{abstract}
Recently a method which estimates the sex of unknown skeletal remains by discriminant functional analysis (DFA) of the patella bone has received much recognition. DFA equation on patella bone is available for South Italian population, Iranian population, Thai population, archeological sample of prehistoric period and also for South Africans of European ancestry. The aim of this study was to derive discriminant functional equation for sex determination from measurements of patella bones in North Indian population The authors have analyzed 31 skeletons (19 males and 12 females) of both sides from the collection in the Department of Anatomy, Post Graduate Institute of Medical Sciences, Rohtak. Seven measurements for both the sides were taken on 62 patella bones of males (19) and females (12). Parameters measured were maximum length, maximum width, maximum thickness, maximum height and width of external and internal articular facets. These measurements were used to determine sex by using discriminant functional analysis. The results of this study exclusively based on patellar dimensions can determine the sex of North Indian population when other long bones, skull and pelvis bones are not available or after major accidental deaths when long ones get fragmented. This discriminant function carried out by statistical analysis will be the future method for sex determination which needs basic data for this bone from their own population:
\end{abstract}

Keywords: Forensic Anthropology, Sex determination, Discriminant function analysis, Patella, North Indian Population

\section{Introduction}

Sex determination is one of the major challenges for the forensic anthropologist within a medicolegal context. Estimation of sex is more reliable if the complete skeleton is available for analysis but in majority of forensic cases human skeletal remains are either incomplete or damaged [1].

The skull, pelvis and long bones are frequently absent or fragmented so sex prediction must be attempted from other parts of skeleton [1].

However the accuracy of sex estimation from other skeletal elements depends on the degree of sexual dimorphism exhibited by the skeleton.

Generally, there are two methods to study for sex determination from skeletal remains viz: morphologic and metric method of studies. The morphologic method involves the observation of sexual traits on pelvic bone for a wide subpubic angle in females. This method is quicker but will have accurate results if the observer has enough experience. On the other hand, the metric method is based on measurements and statistical techniques which doesn't require expertise and can be repeated to validate results [2].

One of the skeletal elements drawing more attention recently is the patella (kneecap). Patella, one of the largest sesamoid bone is situated in front of the knee joint in the tendon of the quadriceps femoris. It is flattened and triangular in shape and has an anterior and posterior surface, three borders, and an apex. The kneecap is a solid element of the human skeleton with no discernible morphological features for determining sex and thus no significant difference is attributed to race. However, being a sesamoid bone that forms within the tendon of the quadriceps muscle, it is very resistant to postmortem changes and so can be available for personal identification purposes even in adverse condition [8].

There are a few studies about determination of sex from patella. The first was made by McWilliam and El Najjar in 1978 [3]. They used water displacement method to calculate the volume of the bone. Most of the male patellas were more than $15 \mathrm{cc}$ and the female were less than $11 \mathrm{cc}$. Introna et al used 80 right patella bones of South Italian population and analysed by univariate discriminant analysis and multivariate discriminant analysis for correct sex determination [1]. The accuracy reported was $83.8 \%$. In their population, Dayal and Bidmos (2005) used maximum height, width and thickness of the patellae in South African Blacks and gained the highest rate of classification of $85 \%$ [4]. Kemkes-Grottenthaler (2005) also used the same method on 82 samples and gained $85 \%$ average accuracy (when sample size was not taken into consideration) [5] Mahfouz and his co-workers (2007) used nonlinear classification methods on 228 samples and gained $90.9 \%$ overall accuracy [6]. Akhlaghi and his co-workers (2010) using 113 patellae from the fresh cadavers of Iranian population found the highest average accuracy of $92.9 \%$ [2]. To add to the literature in India, a recent data on patellar measurements for sex determination had also been recorded in North Bengal population were mean values were documented and discussed [7]. Recently PaoloPhoophalee et al reported $90.5 \%$ accuracy of sex determination on average using all parameters by multivariate discrminant analysis.

Our study utilizing discriminant function analysis will produce an equation to determine sex from this bone.

\section{Materials and Method}

Sixty two unfractured and nonpathological right and left patellae samples of both sexes were obtained from skeletons (19 male, 12 female) belonging to North Indian population 


\section{International Journal of Science and Research (IJSR) \\ ISSN (Online): 2319-7064}

Index Copernicus Value (2013): 6.14 | Impact Factor (2014): 5.611

in the Department of Anatomy of Pt. B .D. Sharma PGIMS, Rohtak.

Seven metrical measurements were recorded using measuring calipers:

Maximum Height $(\mathrm{MH})$ : Maximum linear distance between the tip of the apex and the base.

Maximum Width (MW): Maximum linear distance between the medial and lateral borders.

Maximum Thickness (MT): Maximum distance between the anterior and posterior surfaces.

Height of External Facet (EFH): Maximum distance between the most superior and the most inferior points on the articular facet on the posterior surface.

Width of External Facet (EFW): Linear distance between the lateral border of the patella and the median ridge of the articular facet.

Height Of Internal Facet (IFH): Maximum distance between the most superior and the most inferior points on the articular facet on the posterior surface.

Width of Internal Facet (IFW): Linear distance between the medial border of the patella and the median ridge of the articular facet.

The statistical product and service solution program (SPSS 16) was used to analyze the data. Descriptive statistics including mean, standard deviation were obtained for all variables. After establishing that significant difference exists between male and female mean values for each measurements, discriminant function analyses was performed. The aim of this study was to determine sex using discriminant function analysis from the skeletal collection whose sex, age and time of death were known. Discriminant analysis was applied using discriminant function equation for the determination of sex from all patella variables.

$\mathrm{DF}=\mathrm{a}+\mathrm{b} 1 \times 1+\mathrm{b} 2 \times 2+\ldots+\mathrm{bnxn}$

Where $\mathrm{a}=$ constant,

$\mathrm{b} 1 \mathrm{~b}_{2} \ldots \mathrm{bn}=$ patella variables (anthropometric)

$\mathrm{x} 1 \mathrm{x} 2 \ldots \mathrm{xn}=$ discrminant function coefficients.

$\mathrm{DF}=$ discriminant function .

All possible combinations between the considered parameters were then automatically performed and the discriminant functions were listed in order of highest sex discriminant degree.
Determination of demarcating values for sex determination was done utilizing sectioning point.

Sectioning point $=\left(Z_{m} \times N_{f}\right)+\left(Z_{f} \times N_{m}\right) /\left(N_{m}+N_{f}\right)$

Where $Z_{m}$ and $Z_{f}$ are group centroids for male and female, $\mathrm{N}_{\mathrm{m}}$ and $\mathrm{N}_{\mathrm{f}}$ are number of patella of male and female respectively.

The sectioning point was calculated from group centroids. In cases where the DFA score was less than sectioning point, was considered female and for values of DFA above sectioning point were considered male.

\section{Results}

The results of descriptive statistical analysis were reported in Table I showing the mean, and standard deviation (SD) of right and left side for both the sexes.

The results of all 7 metrical measurements in the present study showed that the average size of the left and right male patella bones were larger than those of the female.

Discriminant function analysis was performed from all seven measurements for both the sides to confirm the sex (Table II and III).

Descriptive statistical analysis on right side reveals the greatest sex difference with the measurement variable of maximum height followed by height of external facet, maximum width, height of internal facet, width of internal facet, width of external facet and the least was by maximum thickness

Table 1: Showing the mean, and standard deviation (SD) of right and left side for both sex

\begin{tabular}{|c|c|c|c|c|c|}
\hline \multirow{2}{*}{ No. } & \multirow{2}{*}{ Variables } & \multicolumn{2}{|c|}{ Male: 19} & \multicolumn{2}{c|}{ Female: 12} \\
\cline { 3 - 6 } & & Mean & SD & Mean & SD \\
\hline 1 & MH -R & 42.9 & 4.8 & 38.1 & 2.8 \\
\hline 2 & MW -R & 42.1 & 3.1 & 39.0 & 3.9 \\
\hline 3 & MT -R & 19.7 & 1.1 & 18.6 & 2.3 \\
\hline 4 & EFH - R & 30.5 & 3.8 & 26.7 & 3.5 \\
\hline 5 & EFW - R & 25.3 & 1.9 & 23.4 & 3.0 \\
\hline 6 & IFH - R & 26.1 & 2.7 & 23.4 & 4.9 \\
\hline 7 & IFW - R & 22.1 & 2.3 & 19.8 & 3.9 \\
\hline 8 & MH -L & 41.7 & 3.4 & 38.3 & 3.5 \\
\hline 9 & MW -L & 41.3 & 3.4 & 37.9 & 4.7 \\
\hline 10 & MT -L & 20.7 & 1.5 & 19.2 & 3.6 \\
\hline 11 & EFH - L & 30.9 & 3.1 & 27.8 & 3.5 \\
\hline 12 & EFW - L & 26.4 & 2.5 & 23.9 & 2.1 \\
\hline 13 & IFH - L & 26.0 & 2.4 & 23.6 & 4.9 \\
\hline 14 & IFW - L & 22.4 & 1.7 & 20.7 & 3.2 \\
\hline
\end{tabular}




\section{International Journal of Science and Research (IJSR) \\ ISSN (Online): 2319-7064}

Index Copernicus Value (2013): 6.14 | Impact Factor (2014): 5.611

Table 2: Direct Discriminate Analysis on Right side

\begin{tabular}{|c|c|c|c|c|c|c|c|}
\hline \multirow[b]{9}{*}{ All (F1) variables } & \multirow{2}{*}{ Variable } & \multirow{2}{*}{$\begin{array}{c}\text { Classification function } \\
\text { coefficient }\end{array}$} & \multicolumn{2}{|c|}{ Group centroids } & \multicolumn{2}{|c|}{ Correctly classified } & \multirow[t]{2}{*}{ Avg accuracy $\%$} \\
\hline & & & $\mathrm{M}$ & $\mathrm{F}$ & $\mathrm{M}$ & $\mathrm{F}$ & \\
\hline & $\mathrm{MH}$ & 0.464 & & & & & \\
\hline & MW & -0.045 & & & & & \\
\hline & MT & -0.074 & & & & & \\
\hline & EFH & 0.145 & & & & & \\
\hline & EFW & 0.011 & & & & & \\
\hline & IFH & -0.043 & & & & & \\
\hline & IFW & -16.424 & 0.835 & -1.323 & 78.9 & 83.3 & 80.5 \\
\hline \multirow{5}{*}{ (F2) 5 variables } & MH & 0.445 & & & & & \\
\hline & MW & -0.0108 & & & & & \\
\hline & MT & -0.097 & & & & & \\
\hline & EFH & 0.087 & & & & & \\
\hline & EFW & -14.458 & 0.786 & -1.245 & 84.2 & 75 & 80.6 \\
\hline \multirow{5}{*}{ (F3) 5 variables } & MT & -0.045 & & & & & \\
\hline & EFH & 0.376 & & & & & \\
\hline & EFW & 0.013 & & & & & \\
\hline & IFH & -0.067 & & & & & \\
\hline & IFW & $0.038-9.516$ & 0.506 & -0.801 & 73.7 & 66.7 & 71 \\
\hline \multirow{4}{*}{ (F4) 4 variables } & EFH & 0.367 & & & & & \\
\hline & EFW & 0.018 & & & & & \\
\hline & IFH & -0.066 & & & & & \\
\hline & IFW & $0.017-9.978$ & 0.504 & -0.798 & 73.7 & 75 & 74.2 \\
\hline
\end{tabular}

Descriptive statistical analysis on the left side reveals the greatest sex differentiation with the measurement variable of maximum height and maximum width followed by height of external facet, width of external facet, height of internal facet, width of internal facet and the least was by maximum thickness.

\section{Discussion}

Patella, a sesamoid bone is often availed intact even after major accidental deaths where long bones easily get fragmented. Males have a comparatively larger muscle build as compared to females thus it could be inferred that this small bone might show a remarkable degree of sexual dimorphism.

For the past three decades, several studies were being carried out in different parts of the World for patellar sexual dimorphism among various populations.

One such pioneer study was conducted by Gunn and McWilliams, using volume of the bone. In his reports the highest average accuracy for sex classification was $88 \%$ for Europeans. Measurements taken on most bones in the body have shown higher mean values for males as compared to females. The patella follows a similar pattern [9]. In our study similar observations were found from mean of all parameters done for male and female patella bones. The maximum mean height of patella bone in males was 42.9 and 38.3 in females for right side and difference in values was also noted on left side, where the value in males was 41.6 and in female it was 39.1.

From table II and III average accuracy has been reported utilizing DFA equation. Maximum height of Patella bone of both sides and maximum width plays a major role in sexual dimorphism if the mean parameter was considered.

Sex determination by subjecting some measurements of the patella was done by O'Connor(1996) [10]; Introna el al:1998 [1]; Kemkes2005 [5]; Bidmos2005 [12]; Dayal and Bidmos 2005 [4]; Akhlaghi2010 [2], and Paolophoophalee et al 2012 [11] on various populations using discriminant function analysis utilizing one; or a few or all various measurements of patella and their accuracy for sex determination were tabulated (Table no. IV). We are aware that patterns of sexual dimorphism vary among populations and that the functions obtained could not have a similar accuracy if applied to different populations. So this study confirms the usage of discriminant functional analysis with patella parameter for sexual dimorphism in North Indian Population.

This bone gains importance in sexual dimorphism. 


\section{International Journal of Science and Research (IJSR) \\ ISSN (Online): 2319-7064}

Index Copernicus Value (2013): 6.14 | Impact Factor (2014): 5.611

Table 3: Direct Discriminate Analysis on Left side

\begin{tabular}{|c|c|c|c|c|c|c|c|}
\hline \multirow{9}{*}{ All (F1) variables } & \multirow[b]{2}{*}{ Variables } & \multirow{2}{*}{$\begin{array}{c}\text { Classification function } \\
\text { coefficient }\end{array}$} & \multicolumn{2}{|c|}{ Group centroids } & \multicolumn{2}{|c|}{ Correctly classified } & \multirow{2}{*}{$\begin{array}{c}\text { Avg } \\
\text { accuracy } \%\end{array}$} \\
\hline & & & M & $\mathrm{F}$ & M & $\mathrm{F}$ & \\
\hline & $\mathrm{MH}$ & 0.266 & & & & & \\
\hline & MW & -0.024 & & & & & \\
\hline & MT & 0.031 & & & & & \\
\hline & EFH & 0.168 & & & & & \\
\hline & EFW & 0.123 & & & & & \\
\hline & IFH & -0.092 & & & & & \\
\hline & IFW & -14.945 & 0.49 & -0.78 & 68.4 & 66.7 & 67.7 \\
\hline \multirow{5}{*}{ (F2) 5 variables } & $\mathrm{MH}$ & 0.262 & & & & & \\
\hline & MW & -0.073 & & & & & \\
\hline & MT & 0.036 & & & & & \\
\hline & EFH & 0.094 & & & & & \\
\hline & EFW & $0.119-14.195$ & 0.46 & 0.73 & 68.4 & 58.3 & 64.5 \\
\hline \multirow{5}{*}{ (F3) 5 variables } & MT & -0.044 & & & & & \\
\hline & EFH & 0.31 & & & & & \\
\hline & EFW & 0.111 & & & & & \\
\hline & IFH & -0.028 & & & & & \\
\hline & IFW & -9.398 & 0.38 & -0.61 & 68.4 & 75 & 71.1 \\
\hline \multirow{4}{*}{ (F4) 4 variables } & EFH & 0.298 & & & & & \\
\hline & EFW & 0.96 & & & & & \\
\hline & IFH & -0.019 & & & & & \\
\hline & IFW & $0.017-9.978$ & 0.38 & -0.61 & 68.4 & 83.3 & 74.2 \\
\hline
\end{tabular}

Table 4: DFA analysis utilizing Patellar parameters on various population

\begin{tabular}{|c|c|c|c|c|}
\hline Authors \& Year & DFA & $\begin{array}{l}\text { Reported } \\
\text { parameter }\end{array}$ & $\begin{array}{l}\text { Accuracy in reported } \\
\text { Patella parameter with } \\
\text { sides }\end{array}$ & Population \\
\hline \multirow[b]{2}{*}{ INTRONA 1998} & UDA & Thickness & Right $83.8 \%$ & South Italian \\
\hline & MDA & Max. Height & Right $83.8 \%$ & $\begin{array}{l}\text { South Italian } \\
\end{array}$ \\
\hline \multirow[b]{2}{*}{ KEMKES 2005} & UDA & Max. Height & $100 \%$ & Prehistoric Skeleton samples from medieval period \\
\hline & MDA & Max. Height & $100 \%$ & Prehistoric Skeleton samples from medieval period \\
\hline \multirow[b]{2}{*}{ BIDMOS et al 2005} & UDA & Max. Height & $85 \%$ & South African Whites \\
\hline & MDA & All parameters & $85 \%$ & South African Whites \\
\hline \multirow[b]{4}{*}{ DAYAL \& BIDMOS 2005} & UDA & Max. Width & $80 \%$ & South African Blacks \\
\hline & \multirow[b]{3}{*}{ MDA } & Max. Width & \multirow[b]{3}{*}{$85 \%$} & \multirow[b]{3}{*}{ South African Blacks } \\
\hline & & Max Height & & \\
\hline & & Max. Thickness & & \\
\hline \multirow[b]{3}{*}{ AKHLAGI et al 2010} & \multirow[b]{3}{*}{ DA } & Max. Width & \multirow[b]{3}{*}{$93 \%$} & \multirow[b]{3}{*}{ Iranian population } \\
\hline & & Max Height & & \\
\hline & & Max. Thickness & & \\
\hline $\begin{array}{l}\text { PAOLO PHOOPHALEE et } \\
\text { al } 2012\end{array}$ & MDA & All parameters & $90.50 \%$ & Northern Thai Population \\
\hline
\end{tabular}

\section{Conclusion}

The implementation of discriminant function analysis based on patella morphometry offers a simple and well studied approach for sex determination on small bones of an individual from incomplete skeleton remains.

From the present study it has shown that mean values for males were higher than those for the females.

The equation derived can be used for sex determination in our group of North Indian population with the highest accuracy of $80.5 \%$ using variables.

\section{Acknowledgement}

All the authors would like to thank Dr. R. Rohilla, Department of Preventive and Social Medicine, PGIMS, Rohtak, for his help in applying DFA for the data in the study.

\section{References}

[1] F. Introna, G.D. Vella, and C.P. Campobasso, "Sex determination by Discriminant analysis of patella measurements", Forensic Science International, XCV, pp. 39-45, 1998.

[2] M. Akhlagi, A. Sheikhazadi, and A. Naghsh, “" Identification of sex in Iranian Population using patella 


\section{International Journal of Science and Research (IJSR) \\ ISSN (Online): 2319-7064}

Index Copernicus Value (2013): 6.14 | Impact Factor (2014): 5.611

dimensions", Journal of Forensic and Legal medicine, XVII: pp150-155. 2010.

[3] El Najjar and K.R. McWilliams, Forensic Anthropology. Charles C. Thomas, Springfield, IL, pp89, 1978.

[4] M.R.Dayal and M.A. Bidmos, " Discriminating sex in South African Blacks using patella dimensions", Journal of Forensic Science, Nov. Vol. L, (6), 2005.

[5] A.Kemkes, Grottenthaler, "Sex determination by Discriminant analysis: an evaluation of the reliability of patella measurements", Forensic Science International, CXLVII, pp 129-133, 2005.

[6] M. Mahfouz, A. Badawi, B. Merkl, E. E. A. Fatah, E. Pritchard, K. Kesler, M. Moore, R. Jantz, and L. Jantz "Patella sex determination by $3 \mathrm{D}$ statistical shape models and nonlinear classifiers", Forensic Science International, CLXXIII, pp. 161-170. 2007.

[7] TK. Jana, S. Giri, H. Roy, M. Kar, S. Santra, Das., "Patellar anthropometry in Sex differentiation- a study in the Nothern Part Of West Bengal, India", Journal of Indian Medical Association, CXI (10), pp. 657-660, 2013.

[8] S. Standring, editor: Williams A., Newell RLM., Collins P et al, Gray's Anatomy: The Anatomical Basis Of Clinical Practice, $39^{\text {th }}$ ed. London: Elsevier Churchill Livingstone, 2005, pp.1472.

[9] Mc Gunn, KR. McWilliams, "A Method For Estimating Sex of The Human Skeleton From The Volume Of The Patella, Talus or Calcaneus", Homo Gottingen, XXXI: pp. 189- 198. 1980.

[10]WG. O'Connor, “The dimorphic sesamoid: differentiating the patella of females and males by height, width and thickness measurements", Master's thesis of arts in the department of Anthropology. University of South Carolina, 1996.

[11] M.A. Bidmos, N. Steinberg, and K.L. Kuykendall, “ Patella measurements of South African whites as sex assessors", HOMO- Journal of Comparative Human Biology, LVI: pp. 69-74, 2005.

[12] P. Phoophalee, S. Prasitwattanaseree, S. Riengrojpitak , P. Mahakkanukrauh, "Sex Determination by Patella Measurements in Thais" , in proceedings of AGRC, Forensic Science Graduate Programme, Faculty of Science, Mahidol Univ., Bangkok, Thailand,2012. 